BENM 2021

International Scientific and Practical Conference "Biotechnology, Ecology, Nature Management"

\title{
INSTALLATION FOR MAKING FRIED CRILL ICE CREAM
}

\author{
Aleksandr A. Krasnichenko (a)*, Dmitry R. Leskevich (b), Dmitriy N. Akimov (c), \\ Vadim V. Tuyakov (d), Gamzat M. Aliev (e) \\ *Corresponding author
}

(a) Department of Refrigeration and Cryogenic Systems, K.G. Razumovsky Moscow State University of Technologies and Management (the First Cossack University), 73, Zemlyanoy Val str., Moscow, Russia, a.krasnichenko@mgutm.ru

(b) K.G. Razumovsky Moscow State University of Technologies and Management (the First Cossack University, 73, Zemlyanoy Val str., Moscow, Russia, dmitry.leskevich@yandex.ru

(c) K.G. Razumovsky Moscow State University of Technologies and Management (the First Cossack University, 73, Zemlyanoy Val str., Moscow, Russia,

(d) K.G. Razumovsky Moscow State University of Technologies and Management (the First Cossack University, 73, Zemlyanoy Val str., Moscow, Russia,

(e) K.G. Razumovsky Moscow State University of Technologies and Management (the First Cossack University, 73, Zemlyanoy Val str., Moscow, Russia

\begin{abstract}
A freezer for roll ice cream is a low rectangular cabinet with a refrigeration system inside, on top of which there are working cooling surfaces, one or two, round, rectangular or square, which are also called "frying". The temperature of such a "fry" can reach - $30^{\circ} \mathrm{C}$. Currently, the Antarctic krill Euphausia superba (hereinafter referred to as krill) is considered as the richest natural source of raw materials. Krill is a valuable and often irreplaceable raw material for the production of feed, food and technical products. Traditionally, krill products are used in seven areas: in aquaculture, in the food industry, in sport fishing, in aquaria, in the production of pet food, in the medical industry and in the pharmaceutical industry. Krill is a storehouse of nutrients and elements: a source of protein, vitamins, minerals and omega-3 polyunsaturated fatty acids. It is characterized by a low fat content, due to which it is easily absorbed by the body. Contains astaxanthin, a natural antioxidant.
\end{abstract}

2672-8575 @ 2022 Published by European Publisher.

Keywords: Element Peltier, Friser, Kril, Rall ice cream 


\section{Introduction}

At the moment, ice cream roll is a relatively new product in the world of desserts. Such a dessert as fried ice cream appeared in our country quite recently, but it is rapidly gaining popularity. Everything new and positive, and most importantly, tasty, is perceived by the public with great enthusiasm, and the unusual taste of krill ice cream, which is one of the most environmentally friendly products on the planet, will further increase interest in such a delicacy. To prepare such a product, a freezer is needed, but despite their huge number and variety, they are all very expensive, noisy, and also large in size, the only difference in which they differ is the number of working surfaces and their form factor. In connection with this, the development of a mobile, universal and inexpensive freezer for ice cream rolls is relevant.

\section{Problem Statement}

The existing freezers for the production of fried ice cream are distinguished by their large dimensions, which negatively affects the convenience of transportation and use of the unit in everyday life.

\section{Research Questions}

- How does the Peltier element work?

- How to design a freezer for making fried ice cream on thermoelectric batteries?

\section{Purpose of the Study}

The aim of this study is to design a plant for the production of fried krill ice cream using thermoelectric batteries.

\section{Research Methods}

\subsection{Element Peltier and the principle of its operation}

The Peltier element is a thermoelectric converter, the principle of operation of which is based on the Peltier effect - the appearance of a temperature difference when an electric current flows (Bulat \& Buzin, 2001). In the English-language literature, Peltier elements are designated TEC (from the English Thermoelectric Cooler - thermoelectric cooler). The device has two sides, and when a constant electric current flows through the device, it transfers heat from one side to the other, so one side cools and the other heats up (Figure 1).

The structure of the Peltier Element is based on one or more pairs of small semiconductor parallelepipeds - one n-type and one p-type, connected in pairs using metal jumpers. Metal bridges simultaneously serve as thermal contacts and are insulated with a non-conductive film or ceramic plate. Pairs of parallelepipeds are connected in such a way that a series connection of many pairs of semiconductors with different types of conductivity is formed, so that at the top there are one sequence of 
connections (n-> p), and opposite ones below (p-> n). Electric current flows sequentially through all parallelepipeds. Depending on the direction of the current, the upper contacts are cooled, and the lower ones are heated - or vice versa. Thus, the electric current transfers heat from one side of the Peltier element to the opposite and creates a temperature difference. If you cool the heating side of the Peltier element, for example, with a radiator and a fan, then the temperature of the cold side becomes even lower. In single-stage cells, depending on the cell type and current, the temperature difference can be up to approximately $70^{\circ} \mathrm{C}$ (Korzun et al., 2014).

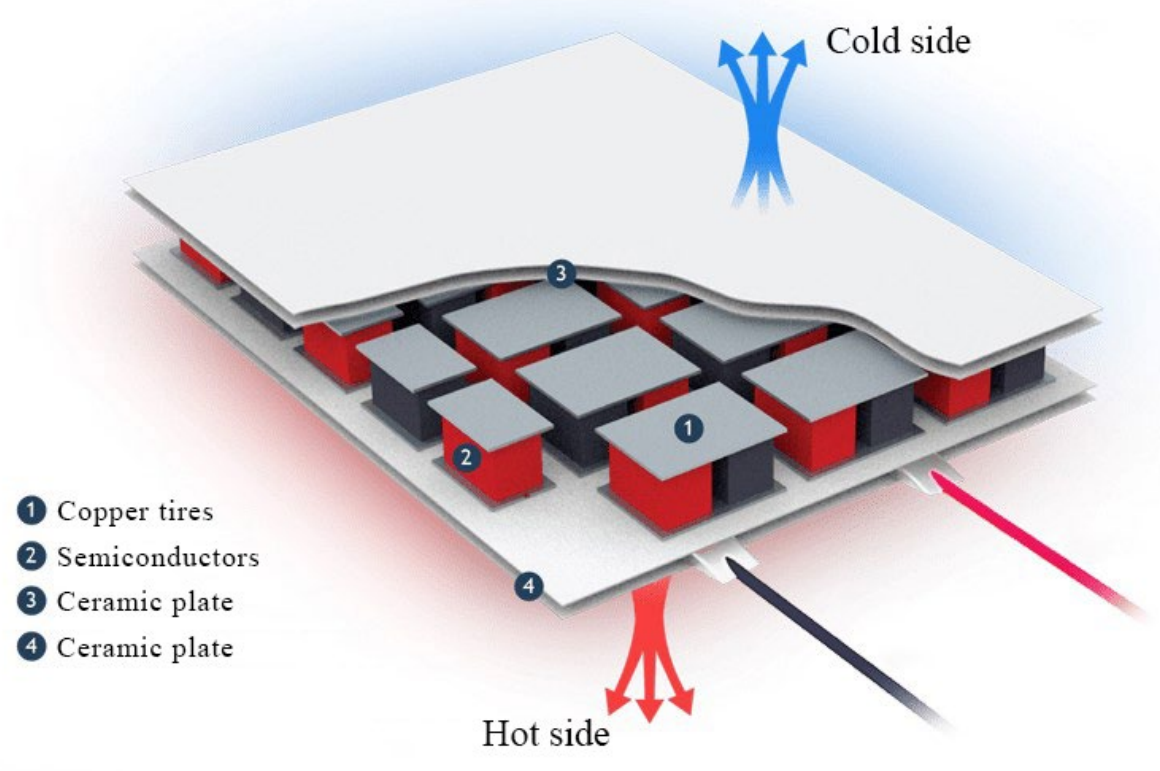

Figure 1. Device of the Peltier element

\subsection{Calculation of the required cooling capacity for the installation}

Initial data for the calculation:

Pasta from krill is laid out on the work surface of the freezer at a temperature of $t_{1}=6{ }^{\circ} \mathrm{C}$; and is extracted from it at a temperature $\mathrm{t}_{2}=-18^{\circ} \mathrm{C}$; the specific heat of krill is equal to $C_{c m}=$ $0,889 \mathrm{kcal} / \mathrm{kg} \cdot{ }^{\circ} \mathrm{C}$; the specific heat of semi-frozen paste to $C_{m}=0,721 \mathrm{kcal} / \mathrm{kg} \cdot{ }^{\circ} \mathrm{C}$; the mixture contains $30.7 \%$ of water; $\mathrm{W}=0,307$; freezing pasta is (cryoscopic temperature) $t_{3}=-3,6^{\circ} \mathrm{C}$ (Nikolaev \& Nikolaev, 2013).

Calculate the percentage of frozen water using the formula:

$$
W_{l}=\left(1-\frac{t_{3}}{t_{2}}\right) \times 100
$$

After substituting the original data into the formula, we get:

$$
W_{l}=\left(1-\frac{-3.6}{-18}\right) \times 100=80 \%
$$

The consumption of cold in the freezer is determined by the formula:

$$
\mathrm{q}=q^{\prime}+q^{\prime \prime}
$$


The value of the specific cold consumption for cooling the mixture is calculated by the formula:

$$
\begin{gathered}
q^{\prime}=\mathrm{C}_{\mathrm{cm}}\left(\mathrm{t}_{1}-\mathrm{t}_{3}\right) \\
q^{\prime}=0,889(6-(-3,6))=8,53 \mathrm{kcal} / \mathrm{kg}
\end{gathered}
$$

The specific consumption of cold for freezing the mixture is determined by the formula:

$$
\begin{gathered}
q^{\prime \prime}=C_{m}\left(t_{3}-t_{2}\right)+80 \frac{W}{100} \frac{W_{l}}{100} \\
q^{\prime \prime}=0,721((-3,6)-(-18))+80 \frac{0,307}{100} \frac{0,8}{100}=10,384 \mathrm{kcal} / \mathrm{kg}
\end{gathered}
$$

Cold consumption in the freezer:

$$
q=8.53+10.384=18.914 \mathrm{kcal} / \mathrm{kg}=79.2 \mathrm{~kJ} / \mathrm{kg}
$$

After conducting the experiment, it turned out that within 5 minutes you can cook about 0.2 kilograms of the product, we determine how much product you can cook in an hour:

$$
\mathrm{G}=0.2 \times 12=2.4 \mathrm{~kg} / \mathrm{h}
$$

Required cooling capacity:

$$
Q_{0}=q \cdot G
$$

Where, $q$ - cold consumption in the freezer, $\mathrm{kJ} / \mathrm{kg}, \mathrm{G}$ - freezer productivity, $\mathrm{kg} / \mathrm{h}$.

$$
Q_{0}=79.2 \times 2.4=190 \mathrm{~kJ} / \mathrm{h}=52.77 \mathrm{~W}
$$

As a result of the calculations, the required power of the freezer for the manufacture of fried krill ice cream was determined, which amounted to $52.77 \mathrm{~W}$.

\subsection{Calculation of Peltier elements}

The elements were calculated based on the selection of the following initial data: thermo-element length $l=40 \mathrm{~mm}$; section $S=5,5 \mathrm{~mm}^{2}$; quality factor of the material $Z=3 \cdot 10^{-3} \mathrm{~K}^{-1}$; thermo-EMF coefficient $\alpha=3,7 \cdot 10^{-4} \mathrm{~V} / \mathrm{K}$; electrical conductivity coefficient $\sigma=8 \cdot 10^{4} \mathrm{Ohm}^{-1} \cdot \mathrm{m}^{-1}$; required cooling capacity $Q_{0}=52,77 \mathrm{~W}$; operating conditions $T_{c}=251 \mathrm{~K}, T_{h}=313 \mathrm{~K}$ (Patrusheva et al., 2013).

We determine the optimal current by the formula (Pnevsky et al., 2018):

$$
I_{\text {opt }}=\alpha \times T_{\mathrm{c}} \times \sigma \times\left(\frac{S}{2 \times l}\right)
$$

Where, $\alpha$ - is the coefficient of thermo-EMF, $\mathrm{V} / \mathrm{K}, T_{\mathrm{c}}$ - is the temperature of the cold side of the element, $K, \sigma$ - is the coefficient of electrical conductivity, $\mathrm{Ohm}^{-1} \cdot \mathrm{m}^{-1}, S$ - section, $\mathrm{mm}^{2}, l$ - element length, mm.

$$
\mathrm{I}_{\text {opt }}=3,7 \cdot 10^{-4} \cdot 251 \cdot 8 \cdot 10^{4} \cdot \frac{0.0000055}{2 \cdot 0,004}=0,51 \mathrm{~A}
$$

We determine the voltage drop by the formula:

$$
U_{0}=\alpha \times T_{c}
$$

Where, $\alpha$ - is the coefficient of thermo-EMF, $\mathrm{V} / \mathrm{K}, T_{c}$ - is the temperature of the cold side of the element, $K$.

$$
U_{0}=3,7 \cdot 10^{-4} \cdot 251=0,092 \mathrm{~V}
$$

We determine the refrigeration coefficient by the formula:

$$
\varepsilon_{d}=\frac{1}{2 T_{h}} \times\left(T_{c}-\frac{2 \times\left(T_{h}-T_{c}\right)}{Z \times T_{c}}\right)
$$


Where, $T_{c}$ - is the temperature of the cold side of the element, $K, T_{h}$ - is the temperature of the hot side of the element, $K, Z$ - is the figure of merit of the material, $K^{-1}$.

$$
\varepsilon_{d}=\frac{1}{2 \cdot 313} \cdot\left(251-\frac{2 \cdot(313-251)}{3 \cdot 10^{-3} \cdot 251}\right)=0,137
$$

We determine the resistance of the thermocouple by the formula:

$$
R_{0}=2 \cdot l / \sigma \cdot S
$$

Where, $\sigma$ - electrical conductivity coefficient, $O h m^{-1} \cdot m^{-1}, S$ - section, $\mathrm{mm}^{2}$, $l$ - element length, mm.

$$
R_{0}=\frac{2 \cdot 0,04}{8 \cdot 10^{4} \cdot 0.0000055}=0,182 \mathrm{Ohm}
$$

We determine the cooling capacity of the thermocouple by the formula:

$$
Q^{\prime}=\frac{\alpha^{2}}{R_{0}} \times\left(\frac{T_{c}^{2}}{2}-\frac{T_{h}-T_{c}}{Z}\right)
$$

Where, $\alpha$ - is the thermo-EMF coefficient, $\mathrm{V} / \mathrm{K}, T_{c}$ - is the temperature of the cold side of the element, $\mathrm{K}, T_{h^{-}}$is the temperature of the hot side of the element, $\mathrm{K}, Z$ - is the figure of merit of the material, $K^{-1}, R_{0}$ - is the resistance of the thermocouple, Ohm.

$$
Q^{\prime}=\frac{\left(3,7 \cdot 10^{-4}\right)^{2}}{0,182} \cdot\left(\frac{251^{2}}{2}-\frac{313-251}{3 \cdot 10^{-3}}\right)=0,008 \mathrm{~W}
$$

We determine the number of thermocouples by the formula:

$$
N=Q_{0} / Q^{\prime}
$$

Where, $Q_{0}$ - is the required cooling capacity, W, $Q^{\prime}$ - is the cooling capacity of the thermocouple, W.

$$
N=\frac{52,77}{0,008}=6596
$$

Determine the power consumed by one thermocouple using the formula:

$$
P_{0}=Q^{\prime} / \varepsilon_{d}
$$

Where, $Q^{\prime}$ - thermocouple refrigerating capacity, $\mathrm{W}, \varepsilon_{d}$ - coefficient of performance.

$$
P_{0}=\frac{0.008}{0.137}=0.0583 \mathrm{~W}
$$

We determine the power of the power supply by the formula:

$$
P=P_{0} \cdot N
$$

Where, $P_{0}$ - is the power consumed by one thermocouple, $\mathrm{W}, N$ - is the number of thermocouples.

$$
P=0.0583 \times 6596=385 W
$$

We determine the heat of hot junctions by the formula:

$$
Q_{h}=P+Q_{0}
$$

Where, $P$ - is the power of the power supply, $\mathrm{W}, Q_{0}$ - is the required cooling capacity, $\mathrm{W}$.

$$
Q_{h}=385+52.77=438 \mathrm{~W}
$$

We determine the voltage of the power source by the formula:

$$
U_{p}=U_{0} \times N
$$

Where, $U_{0}$ - is the voltage drop, $\mathrm{V}, N$ - is the number of thermocouples. 


$$
U_{p}=0.092 \times 6596=607 \mathrm{~V}
$$

It is proposed to connect all the elements in parallel, this will provide additional reliability of the installation, and if one of the elements fails, the installation will not stop working.

$$
U_{p}=\frac{607}{48}=12 \mathrm{~V}
$$

The total power should be calculated, taking into account that an additional $15-20 \%$ of the power consumed by the elements will be spent on the pump for water cooling, as well as on the fan for air cooling. According to the formula:

$$
\mathrm{P}_{\text {gen }}=\mathrm{P}+0,15 \cdot \mathrm{P}
$$

Where, $\mathrm{P}$ - is the power consumed by the elements, W.

$$
\mathrm{P}_{\text {gen }}=385+0.15 \times 385=443 \mathrm{~W}
$$

Figure 2, shows the design of the installation on Peltier elements.

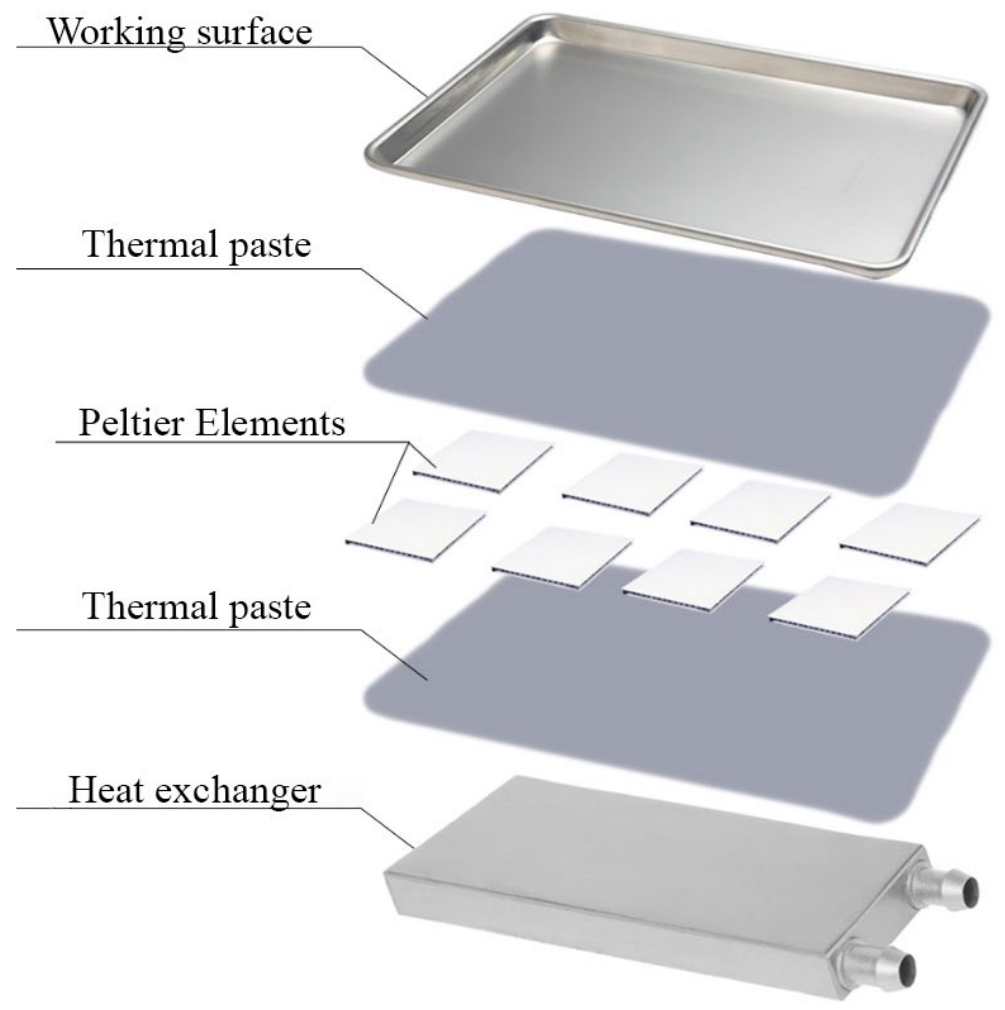

Figure 2. Installation diagram on Peltier elements

As a thermal paste, it is supposed to use one of the most common. Thermal paste KPT-8 Connector KPT-8, which removes heat from heating elements and improves heat transfer between contacting surfaces. Complies with GOST 19783-74.

Specifications:

- The color of the paste is white; 
- Thermal conductivity - 0.8-1 W/mK;

- Specific resistance - $1011 \mathrm{Ohm} / \mathrm{cm}$;

- Dielectric strength - 2 - $5 \mathrm{~kW} / \mathrm{mm}$;

- Tangent of dielectric losses at $10 \mathrm{MHz}-0.005$;

- Operating temperatures - $-60 \ldots+180^{\circ} \mathrm{C}$

Figure 3 shows a radiator in which heat energy from the hot side of the unit will be removed.

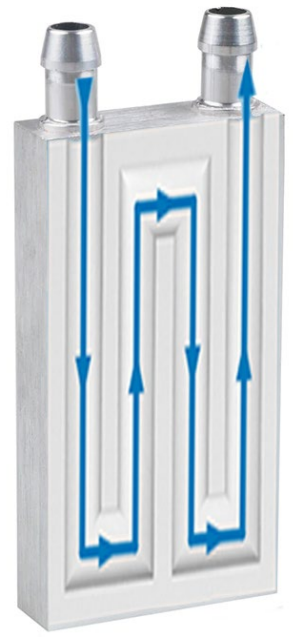

Figure 3. Water cooling heat exchanger design

Figure 4 shows arrangement of Peltier elements under the working surface arrangement.

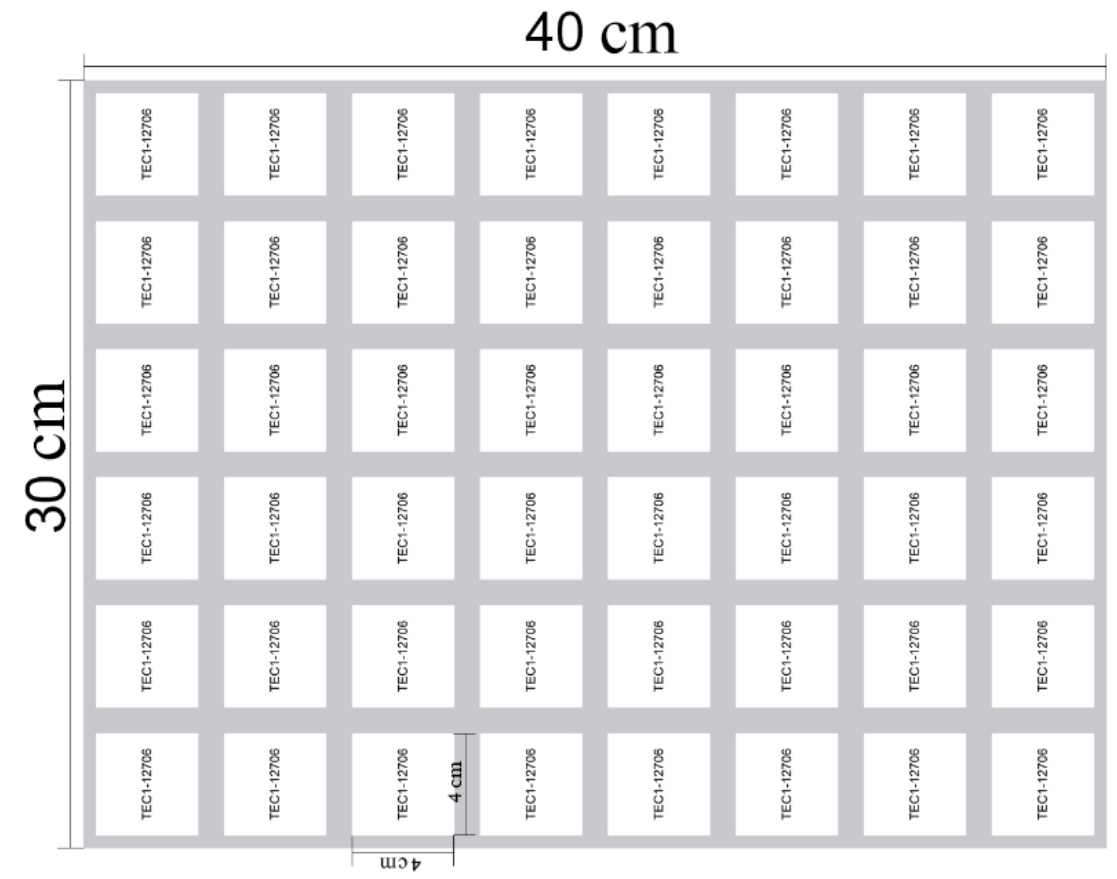

Figure 4. Arrangement of Peltier elements under the working surface 


\section{Findings}

Based on the results of the calculation and the type of the selected equipment, a layout diagram of a freezer for the manufacture of fried ice cream rolls was proposed, which is shown in Figure 5. The advantage of the proposed scheme is its compactness, which makes it possible to expand the scope, facilitate transportation and simplify the operation of the proposed freezer in comparison with classical vapor compression installations of such type.

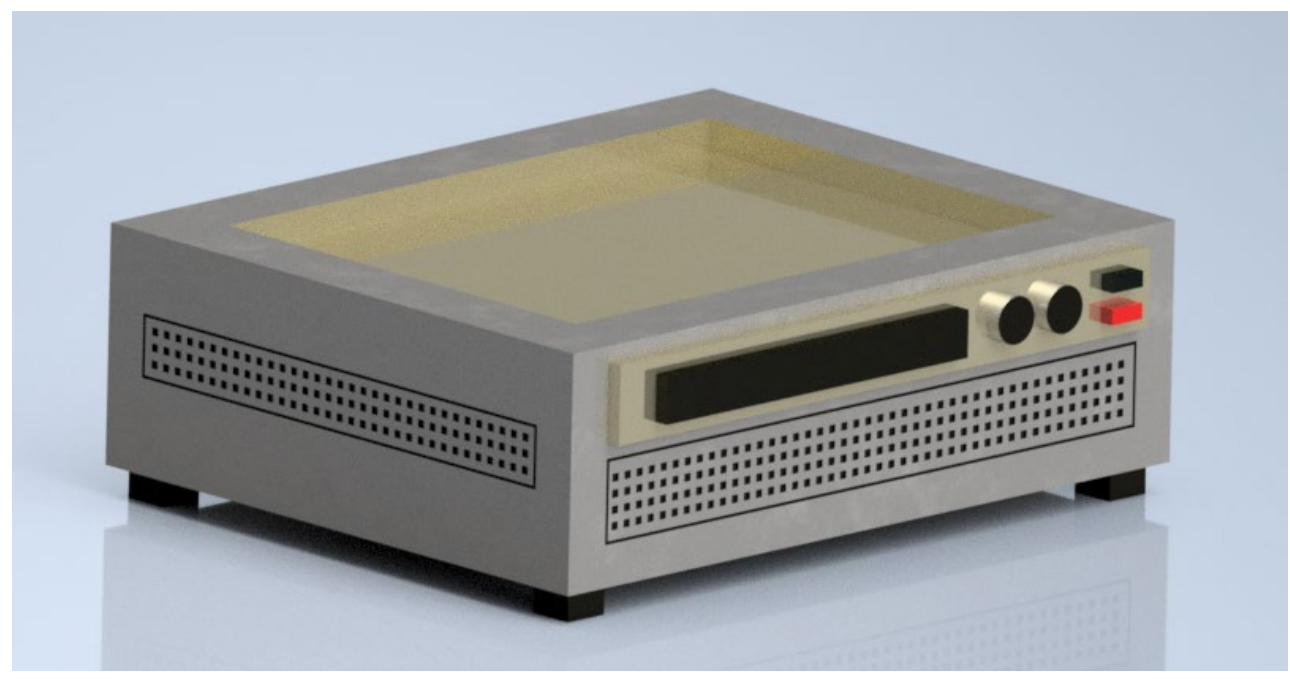

Figure 5. 3D installation model

The method of making a krill ice cream roll and its stages:

1. The product is evenly distributed over the work surface (figure 6).

2. Freeze the product on the work surface to a temperature of $-22^{\circ} \mathrm{C}$, while the holding time is from 1 to 2 minutes.

3. We make (twist) the roll. For a good appearance of the rolls, the recommended layer thickness is up to $2 \mathrm{~mm}$, and the length up to $100 \mathrm{~mm}$. (Figure 7).

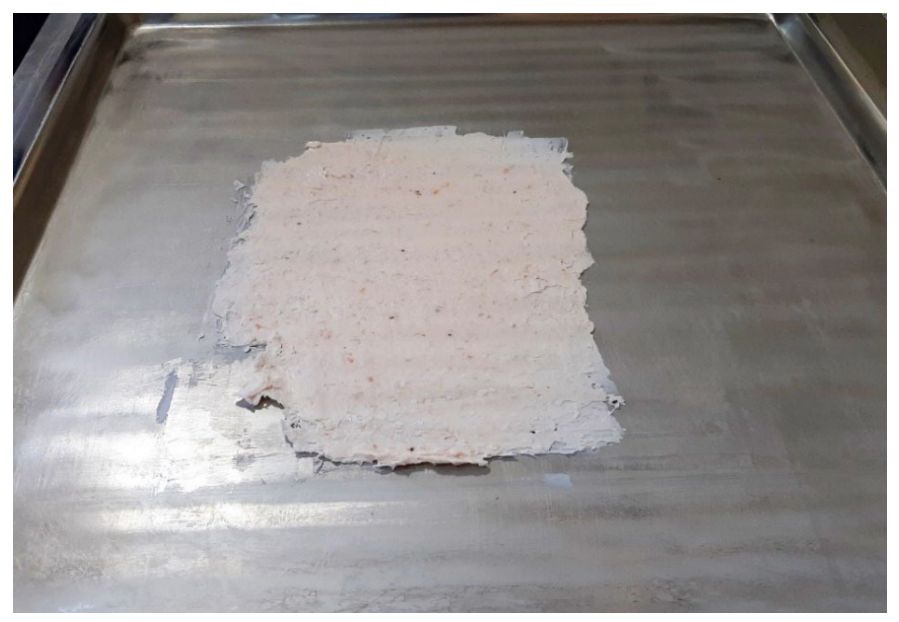

Figure 6. Distributed paste over the work surface 


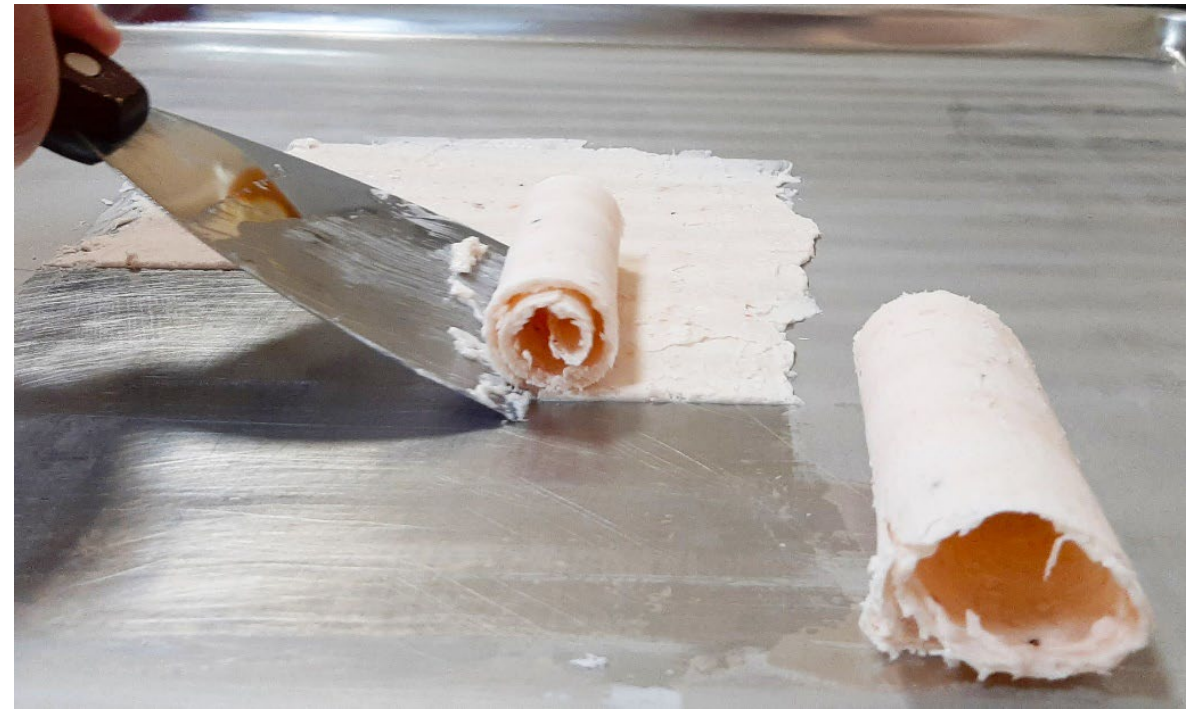

Figure 7. Krill ice cream roll making technology

\section{Conclusion}

A freezer for making a roll of krill ice cream on Peltier elements has been designed and calculated. A distinctive feature of the proposed installation is mobility and availability, which allows the installation to be used both in everyday life and for commercial purposes. By replacing the mixture of dairy products with sugar and baking powder in the technology of making fried ice cream for such a product as krill, which is one of the most environmentally friendly and healthy foods, we have a positive effect on human health and longevity.

\section{References}

Bulat, L. P., \& Buzin, E. V. (2001). Thermoelectric Cooling Devices: Method. Instructions for students "Technique and Physics of Low Temperatures". - SPb.: SPbGUNiPT.

Korzun, Y. V., Rebik, S. T., Kozlova, S. L., Bogomolov V. V., \& Zhuk, N. N. (2014). Promising directions for processing Antarctic krill. Proceedings of the Southern Research Institute of Fisheries and Oceanography, 52, 131-148.

Nikolaev, B. L., \& Nikolaev, L. K. (2013). Processes of freezing ice cream mixtures, calculations and arrangement of freezers: Textbook-method. Allowance. - SPb.: NRU ITMO; IHiBT.

Patrusheva, T. N., Podorozhnyak, S. A., \& Shelovanova, G. N. (2013). Thermoelectric figure of merit in a low-dimensional semiconductor medium. Journal of Siberian Federal University. Engineering \& Technologies, 6, 657-664.

Pnevsky, R., Kovalik, R., \& Sadovski, E. (2018). Fuzzy control of the Peltier element. Young scientist international scientific journal, 9(195), 49. 